\begin{tabular}{|c|c|c|c|c|c|c|}
\hline \multirow{4}{*}{ Impact Factor: } & ISRA (India) & $=3.117$ & SIS (USA) & $=0.912$ & ICV (Poland) & $=6.630$ \\
\hline & ISI (Dubai, UAE & $=\mathbf{0 . 8 2 9}$ & РИНЦ (Russia) & $=0.156$ & PIF (India) & $=1.940$ \\
\hline & GIF (Australia) & $=0.564$ & ESJI (KZ) & $=5.015$ & IBI (India) & $=4.260$ \\
\hline & JIF & $=1.500$ & SJIF (Morocco) & $=5.667$ & & \\
\hline
\end{tabular}

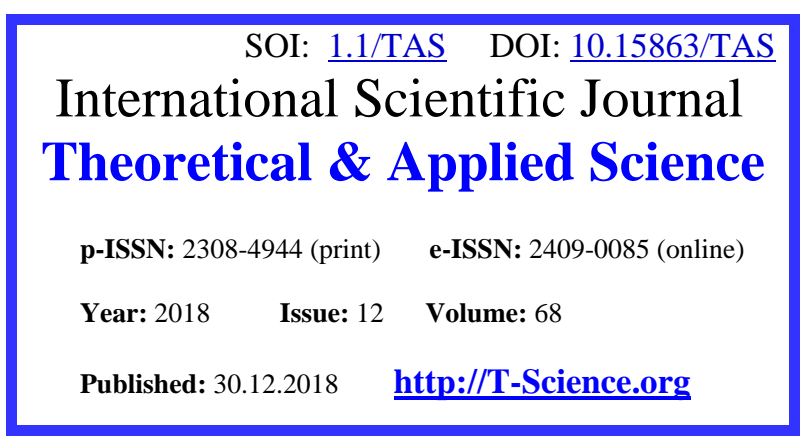

SECTION 25. Technologies of materials for the light and textile industry.
QR - Issue

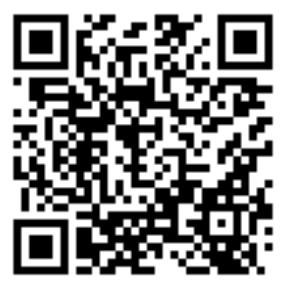

QR - Article

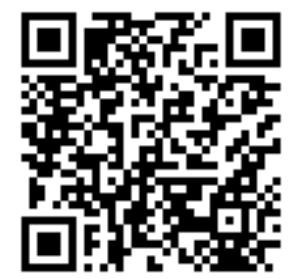

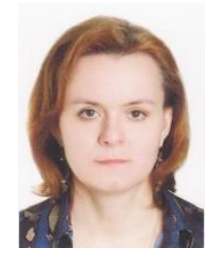

Elena Anatolievna Chalenko candidate of technical Sciences, Associate Professor Department of Artistic modelling, design and technology of garments The Kosygin State University

of Russia (Kosygin University ) ele-ela@yandex.ru

\title{
THE INFLUENCE OF MATERIAL PROPERTIES ON DESIGN SOLUTIONS AND TECHNOLOGICAL PROCESSES IN THE MANUFACTURE OF CORSELETS
}

\begin{abstract}
The article is devoted to the analysis of the properties of different materials used in the production of corsets of underwear products and their impact on the design and technological solutions of these products. Practical recommendations on the selection of materials in packages in the manufacture of corsets and underwear products and the choice of design solutions of the connecting and edge seams are given.

Key words: material, package of materials, stitching, seam, fabric, knitted fabric, corset and linen product, allowance.

Language: Russian

Citation: Chalenko, E. A. (2018). The influence of material properties on design solutions and technological processes in the manufacture of corselets. ISJ Theoretical \& Applied Science, 12 (68), 365-372.

Soi: http://s-o-i.org/1.1/TAS-12-68-55 Doi: crossef https://dx.doi.org/10.15863/TAS.2018.12.68.55

\section{ВЛИЯНИЕ СВОЙСТВ МАТЕРИАЛОВ НА КОНСТРУКТИВНЫЕ РЕШЕНИЯ И ТЕХНОЛОГИЧЕСКИЕ ПРОЦЕССЫ ИЗГОТОВЛЕНИЯ КОРСЕТНО-БЕЛЬЕВЫХ ИЗДЕЛИЙ}

Аннотация: Статья посвящена анализу свойств различных материалов, используемых при производстве корсетно-бельевых изделий и их влиянию на конструктивные и технологические решения данных изделий. Даны практические рекомендации по подбору материалов в пакеты при изготовлении корсетно-бельевых изделий и выбору конструктивных решений соединительных и краевых швов.

Ключевые слова: материал, пакет материалов, строчка, иов, ткань, трикотажное полотно, корсетно-бельевое изделие, припуск.
\end{abstract}

\section{Введение.}

В процессе производства [1] и при эксплуатации [2] корсетно-бельевых изделий проявляются такие свойства материалов, которые обязательно необходимо учитывать при производстве одежды. Эти свойства существенно влияют как на конструктивные особенности, так и на организацию технологических процессов раскроя, пошива и окончательной отделки швейных изделий $[3,4]$. Они диктуют способы ухода за изделиями. К таким свойствам относятся: толщина и поверхностная плотность материала, его растяжимость, жесткость, тангенциальное сопротивление, раздвижка нитей в швах, осыпаемость, прорубаемость, термостойкость, формовочная способность и формоустойчивость, усадка $[5,6]$.

Объекты и методы исследования. Толщина материала и прямо связанная с ней поверхностная плотность влияют на: конструкцию изделия, величину припусков, ширину и конструкцию швов, обусловливают выбор прокладочных материалов. Чем толще материал, тем большую величину припусков необходимо предусматривать при разработке конструкции изделия. Если материалы толстые, необходимо увеличивать ширину швов, используя при этом швы, конструкция которых позволяет минимизировать количество слоев 


\begin{tabular}{|c|c|c|c|c|c|c|}
\hline \multirow{4}{*}{ Impact Factor: } & ISRA (India) & $=3.117$ & SIS (USA) & $=0.912$ & ICV (Poland) & $=6.630$ \\
\hline & ISI (Dubai, UAE & $=0.829$ & РИНЦ (Russia) & $=0.156$ & PIF (India) & $=1.940$ \\
\hline & GIF (Australia) & $=0.564$ & ESJI (KZ) & $=\mathbf{5 . 0 1 5}$ & IBI (India) & $=4.260$ \\
\hline & JIF & $=1.500$ & SJIF (Morocco) & $=5.667$ & & \\
\hline
\end{tabular}

материалов в месте соединения (стачные вразутюжку, накладные с открытыми срезами, расстрочные). Для изделий из толстых тканей выбирают более толстые и жесткие прокладки. От толщины материала зависит число полотен в настиле при раскрое. Чем толще ткань, тем меньше полотен в настиле. При увеличении толщины материала увеличивается и расход скрепляющих материалов (ниток). В зависимости от толщины материала выбирают тип швейного оборудования, регулируют высоту подъема зубчатой рейки и давление лапки на материал.

\section{Результаты и обсуждение.}

Растяжимость материалов в различных направлениях и повышенную растяжимость эластичных полотен необходимо учитывать при изготовлении корсетно-бельевых изделий. Для предохранения швов от разрушения при эксплуатации изделий необходимо, чтобы растяжимость строчки и растяжимость материала были соизмеримы не только между собой, но и с величиной нагрузки, которую испытывает изделие в процессе эксплуатации. Это достигается следующими путями: использованием кромки вдоль шва для уменьшения растяжимости строчки; применением в структуре шва стежков легко деформируемых переплетений (цепных, обметочных); применением швейных ниток повышенной растяжимости (лавсановых, капроновых) [7].

Большое влияние на растяжимость швов оказывают технологические параметры пошива: частота строчки и натяжение ниток на швейной машине. Увеличение натяжения ниток на швейной машине уменьшает растяжимость шва. При увеличении частоты стежков в строчке возрастает растяжимость швов. Изменяя длину стежка и натяжение ниток на швейной машине, можно добиться необходимой растяжимости и прочности швов.

Жесткость материалов при их переработке в швейном производстве и в процессе эксплуатации готовых изделий является негативным свойством. Одежда из жестких материалов создает дискомфорт, затрудняет движения. Вместе с тем при изготовлении корсетно-бельевых изделий для придания им требуемой формы необходима определенная жесткость. Жесткость текстильных материалов влияет не только на формоустойчивость изделий, но и на технологический процесс их изготовления. Повышенная жесткость материалов затрудняет их раскрой из-за интенсивного нагрева режущих элементов раскройного оборудования. При стачивании материалов повышенной жесткости наблюдается значительное повышение температуры иглы швейной машины, что приводит к уменьшению прочности и увеличению обрывов швейных ниток; увеличивается число повреждений стачиваемых материалов.

У текстильных материалов силы трения и сцепления проявляются одновременно. Их характеристикой является коэффициент тангенциального сопротивления, который влияет на такие свойства текстильных материалов, как сопротивление истиранию, продвигаемость, скольжение материала, устойчивость к осыпанию срезов ткани, распускаемость трикотажа и др. При раскрое и стачивании деталей из материалов с небольшим коэффициентом тангенциального сопротивления легко происходит смещение деталей, что приводит к перекосу, деформации и стягиванию деталей и швов. При раскрое может происходить скольжение тканей, которое зависит от характера их поверхности, т. е. от гладкости применяемых нитей и их переплетения. Ткани с гладкой поверхностью скользят в настиле, что может привести к смещению полотен и искажению кроя. При раскрое таких тканей уменьшают число полотен в настиле, применяют прокладки из бумаги и специальные зажимы для скрепления настила.

Для снятия остаточного напряжения трикотажных полотен необходима отлежка полотна в течение 24 часов в размотанном состоянии перед настиланием. Легкорастяжимые полотна настилают с минимальным постоянно контролируемым натяжением. При очень долгом хранении, а также, для того чтобы облегчить релаксацию настила выполняют надрезание настила по ширине полотна через каждые 2-2,5 метра в межлекальной зоне между деталями [8].

Кромки полотен выравнивают при настилании, поскольку попытки выровнять кромки после настилания могут привести к вытяжке, неодинаковому напряжению и «зарезке» деталей. Высоту настила формируют в пределах 15 см. В качестве основных рекомендаций предлагается формировать настил из трикотажных полотен высотой 48 слоев. Для предотвращения закручиваемости деталей кроя при настилании некоторых материалов необходимо прокладывать в настил плотную бумагу через каждые 2 слоя. Это особенно желательно выполнять при раскрое мелких деталей. Трикотажные полотна, содержащие волокно «лайкра», обычно не скользят.

Для облегчения раскроя полотен, а также для предотвращения скольжения полотен могут быть использованы зажимы, скобы или иглы. Кроме того, слои материала могут быть соединены между собой путем сверления специальным нагреваемым сверлом в местах межлекальных выпадов. 


\begin{tabular}{|c|c|c|c|c|c|c|}
\hline \multirow{4}{*}{ Impact Factor: } & ISRA (India) & $=3.117$ & SIS (USA) & $=0.912$ & ICV (Poland) & $=6.630$ \\
\hline & ISI (Dubai, UAI & $=0.829$ & РИНЦ (Russia) & $=0.156$ & PIF (India) & $=1.940$ \\
\hline & GIF (Australia) & $=0.564$ & ESJI (KZ) & $=5.015$ & IBI (India) & $=4.260$ \\
\hline & JIF & $=1.500$ & SJIF (Morocco) & $=5.667$ & & \\
\hline
\end{tabular}

Большое значение трение и сцепление имеют при эксплуатации одежды. Например, подкладочные ткани должны иметь пониженный коэффициент тангенциального сопротивления, чтобы уменьшались силы трения и сцепления, возникающие при соприкосновении поверхности изделия и тела человека. Коэффициент тангенциального сопротивления для различных материалов изменяется в широком диапазоне и зависит от волокнистого состава, вида переплетения, плотности, способа отделки, вида покрытия и т.д.

Для облегчения перемещения материалов, имеющих повышенный коэффициент трения, их стачивание выполняют на швейных машинах с применением тефлоновой лапки и рольпресса или на швейных машинах с дифференциальным механизмом перемещения материалов.

Закручиваемость срезов трикотажных полотен является их существенным недостатком, поскольку вызывает целый ряд осложнений в процессах изготовления изделий. Из-за закручиваемости краев трикотажа приходится применять при настилании и разрезании специальные зажимы по кромкам настила. Так же это свойство вносит осложнение в при комплектовке кроя и проверке его качества. Так как достаточно отделить от пачки кроя одну деталь, как она тут же начинает закручиваться. Поэтому раскроенные изделия из трикотажа нельзя комплектовать поштучно; в пачке же за счет сил тангенциального сопротивления между слоями трикотаж удерживается в расправленном состоянии [9]. В ряде случаев данное свойство трикотажа также используют в качестве отделки швейных изделий.

Для получения ровных швов и повышения производительности труда стачивающеобметочные машины, на которых выполняется большинство операций по изготовлению изделий из трикотажных полотен, имеют в своей конструкции ножевые механизмы, т. е. края обрезаются прежде, чем будет проложена строчка. Для того чтобы заложенный на шов припуск не был срезан на машины устанавливают специальные расправители краев.

Раздвижка нитей в ткани характеризуется смещением нитей одной системы относительно, нитей другой системы (основы относительно утка или утка относительно основы). Раздвижка возникает из-за недостаточного сопротивления взаимному перемещению нитей в ткани. Она может явиться следствием структурных особенностей ткани - наличия крайних фаз строения (в отдельных тканях, например, поплине), использования раппорта с большими перекрытиями (в атласных тканях), применения нитей пониженной крутки, уменьшения плотности ткани, а также нарушения строения и отделки ткани при ее производстве [10]. В готовых изделиях раздвижка нитей проявляется преимущественно в области швов.

Осыпаемость ткани характеризуется смещением нитей около срезанного края ткани до спадания нитей одной системы с нитей другой (основы с утка или утка с основы). Осыпаемость ткани является следствием недостаточного закрепления нитей в структуре ткани; она обусловливается главным образом небольшими силами трения и взаимного сцепления, возникающими между нитями основы и утка. Осыпаемость ткани обусловлена видом волокна и переплетением ткани, структурой пряжи, плотностью ткани, фазой ее строения, линейной плотностью основы и утка, направлением среза ткани и другими факторами.

Наибольшей осыпаемостью обладают ткани из химических нитей, наименьшей - шерстяные и хлопчатобумажные ткани. Причиной этого являются различия в коэффициентах трения, сцепляемости волокон и природе нитей. Осыпаемость тканей в значительной степени зависит от их волокнистого состава. В порядке возрастания степени осыпаемости ткани располагаются в такой последовательности: хлопчатобумажные; из натурального шелка; из вискозной пряжи; из ацетатных, триацетатных, лавсановых, капроновых нитей. Большое влияние на осыпаемость оказывает вид переплетения ткани (осыпаемость тканей сатинового переплетения в 3 раза больше, чем полотняного). Наибольшей осыпаемостью характеризуются ткани атласных переплетений с большими перекрытиями нитей, наименьшей - ткани полотняного переплетения. Уменьшение плотности тканей по одной из систем нитей вызывает увеличение осыпаемости нитей противоположной системы.

Осыпаемость срезов тканей, расположенных под различными углами к нитям основы или утка, неодинакова. Наибольшую осыпаемость имеют срезы тканей вдоль нитей основы, утка или под углом не более $15^{\circ}$ к нитям как основы, так и утка. При расположении среза под углом $45^{\circ}$ к той или иной системе нитей осыпаемость минимальная. Повышенная осыпаемость срезов деталей увеличивает расход материалов и затраты труда на изготовление изделий, ухудшает их качество. Осыпаемость ткани существенно влияет на износостойкость одежды, так как значительное осыпание приводит к быстрому разрушению швов в процессе эксплуатации одежды. Для предупреждения разрушения швов в результате осыпания ткани обметывают срезы, проклеивают края деталей, увеличивают ширину швов и применяют швы специальных конструкций. 


\begin{tabular}{|c|c|c|c|c|c|c|}
\hline \multirow{4}{*}{ Impact Factor: } & ISRA (India) & $=3.117$ & SIS (USA) & $=0.912$ & ICV (Poland) & $=6.630$ \\
\hline & ISI (Dubai, UAE & $=0.829$ & РИНЦ (Russia) & $=0.156$ & PIF (India) & $=1.940$ \\
\hline & GIF (Australia) & $=0.564$ & ESJI (KZ) & $=\mathbf{5 . 0 1 5}$ & IBI (India) & $=4.260$ \\
\hline & JIF & $=1.500$ & SJIF (Morocco) & $=5.667$ & & \\
\hline
\end{tabular}

Устойчивость к осыпанию срезов швов, обработанных вподгибку, на 25-30\% больше, а с закрытым срезом в три раза больше, чем обметанных срезов. Наиболее устойчивы к осыпанию срезы в двойном запошивочном и окантовочном швах. Надежность закрепления срезов возрастает с увеличением, как ширины обметочной строчки, так и числа стежков на $1 \mathrm{~cm}$. C увеличением ширины строчки при обметывании от 3 до 6 мм устойчивость срезов к осыпанию возрастает в 3-5 раз. При увеличении частоты строчки от трех до шести стежков в $1 \mathrm{~cm}$ строчки устойчивость срезов к осыпанию возрастает в 2,5-7 раз.

Прорубаемость при стачивании текстильного материала характеризуется частичным или полным разрушением отдельных нитей материала иглой в процессе пошива. Разрушение нитей, проявляющееся после стирки изделий, принято называть скрытым прорубанием. Прорубание текстильного материала приводит к ухудшению внешнего вида изделия, снижению прочности шва, а, в конечном счете - к непригодности изделия для эксплуатации. Степень прорубания материала зависит от ряда факторов: структуры, плотности, жесткости, вида отделки исходной пряжи и самого материала, а также типа и размера иглы, натяжения швейной нитки и др.

Повреждения в процессе стачивания возникают при изготовлении изделий из любых плотных материалов: тканей, трикотажа. Прорубание особенно опасно для трикотажа, так как оно вызывает распускание петель. Значительное влияние на прорубание оказывает отделка, используемая при изготовлении материала. Определенные виды отделки материала приводят к уменьшению его коэффициента трения об иглу, снижают прорубание при стачивании.

На прорубание материала, обусловленное процессом пошива, существенно влияет толщина (номер) машинной иглы. С изменением номера машинной иглы от 90 до 100 прорубание трикотажных полотен может увеличиваться в 1,5 3 раза. Швейная нить оказывает меньшее влияние на частоту повреждений, чем игла. Но все же, чем мягче швейная нитка, тем меньше прорубание обрабатываемого материала. Например, меньше прорубаются швы, выполненные с использованием в качестве швейных ниток пряжи (хлопчатобумажной и штапельной полиэфирной), больше - с применением армированных, комплексных синтетических или прозрачных капроновых швейных ниток (мононитей). При частых обрывах швейной нитки число повреждений иглой стачиваемых материалов значительно возрастает, так как на прорубание влияет температура иглы, которая резко повышается в результате обрыва нитки. Для предотвращения прорубания материалов необходимо тщательно подбирать игольную пластину. Диаметр отверстия игольной пластины должен превышать диаметр иглы не более чем в 1,7-1,8 раза [11].

Термостойкость - это способность материала реагировать без изменения физических свойств на продолжительные или кратковременные нагревы. Термостойкость материала обычно характеризуется максимальной (критической) температурой. При температуре выше критической наступает ухудшение свойств материала, препятствующее его использованию. В процессе изготовления швейных изделий текстильные материалы подвергаются температурным воздействиям при влажнотепловой обработке и обработке на швейной машине разогретой иглой.

Самую низкую термостойкость имеют хлориновые волокна. Их размягчение наблюдается при температуре $95-100^{\circ} \mathrm{C}$. У полиамидных волокон размягчение может наступить при температуре 170-235 ${ }^{\circ}$ C (в зависимости от модификаций), у полиэфирных при температуре $220-240^{\circ}$ С. Для натуральных волокон (шерсти, шелка, хлопка, льна) наиболее характерно разложение, проявляющееся в уменьшении их прочности (для шерсти происходящее при температуре, близкой к $235^{\circ} \mathrm{C}$, а для шелка - при температуре $150-170^{\circ} \mathrm{C}$ ).

Повышенный нагрев при утюжке и прессовании материалов уменьшает их прочность, устойчивость к многократным изгибам, истиранию, изменяет цвет материала. При кратковременном нагреве процессы изменения физических свойств материалов имеют обратимый характер. Действие повышенной температуры можно регулировать уменьшением времени контакта. При длительном воздействии наблюдаются необратимые процессы теплового старения.

При стачивании текстильных материалов вследствие трения иглы о материал происходит нагрев иглы. Степень нагрева зависит от структуры, толщины, плотности, жесткости обрабатываемых материалов, скорости пошива, конфигурации иглы, чистоты обработки ее поверхности и т.п. Чем больше плотность, жесткость, толщина стачиваемых материалов, тем выше температура нагрева иглы. Игла может нагреваться до $400^{\circ}$ С. В этом случае при стачивании материалов, содержащих химические волокна, материалы размягчаются и налипают на поверхность иглы. При использовании синтетических ниток может происходить размягчение, которое вызывает ее обрыв. Для снижения нагрева иглы при стачивании материалов рекомендуется использовать 


\begin{tabular}{|c|c|c|c|c|c|c|}
\hline \multirow{4}{*}{ Impact Factor: } & ISRA (India) & $=3.117$ & SIS (USA) & $=0.912$ & ICV (Poland) & $=6.630$ \\
\hline & ISI (Dubai, UAE & $=0.829$ & РИНЦ (Russia) & $=0.156$ & PIF (India) & $=1.940$ \\
\hline & GIF (Australia) & $=0.564$ & ESJI (KZ) & $=5.015$ & IBI (India) & $=4.260$ \\
\hline & JIF & $=1.500$ & SJIF (Morocco) & $=5.667$ & & \\
\hline
\end{tabular}

швейные машины с принудительным охлаждением иглы и применять дополнительную обработку (смачивание) поверхности ниток кремнийорганическими препаратами.

Способность материала образовывать пространственную форму деталей одежды путем изменения геометрических размеров материала на отдельных участках и устойчиво сохранять ее называется формовочной способностью материала [12]. Формовочная способность материала характеризуется двумя стадиями: формообразованием и закреплением формы. Формообразование служит для создания в одежде складок, объемной формы полочек, рукавов, для формования воротника и других деталей. Устойчивое закрепление формы и ее сохранение - непременное условие хорошего внешнего вида изделия в процессе эксплуатации [13].

Формообразование текстильных материалов возможно благодаря тому, что в них значительный объем занимает воздух (плотность большинства видов тканей не превышает 0,5 мг/мм3, пористость около 50-80\%) и имеются подвижные и устойчивые связи в структуре материала. Поэтому текстильные материалы легко поддаются различным видам деформаций (изгибу, растяжению, сжатию), определяющим его способность к формообразованию.

Формообразование тканей - следствие принудительного изменения угла между нитями основы и утка. Способность тканей к формообразованию оценивают удлинением при растяжении под действием нагрузки 1-2 даН, приложенной к пробе, выкроенной под углом $45^{\circ}$. При формообразовании, происходящем в результате деформаций (изгиба, растяжения, сжатия, утонения, изменения угла между нитями), нарушается равновесное состояние структуры материала. Закрепить деформацию текстильного материала можно при влажнотепловой обработке деталей и изделия. Для устойчивого закрепления формы деталей одежды используют термоклеевые прокладочные материалы (полиэтиленовую сетку), ткани и нетканые полотна с клеевым покрытием, термоклеевые химические композиции, наносимые на ткани верха.

Для получения устойчивой формы хлопчатобумажные и вискозные ткани подвергаются предварительной обработке под названием форниз - формование несминаемых изделий. Несминаемость тканей с обработкой форниз повышается на 30-50\%, возрастает устойчивость складок. Изделия из тканей, обработанных способом форниз, подвергают влажно-тепловой обработке с увлажнением при температуре не выше $140^{\circ} \mathrm{C}$ и времени прессования 30-40 с. Устойчивое закрепление формы изделий можно обеспечить благодаря использованию в структуре материала термопластичных волокон. При влажно-тепловой обработке волокна расправляются, фиксируя созданную форму.

В процессе влажно-тепловой обработки в результате действия влаги, пара, повышенной температуры могут изменяться линейные размеры текстильных материалов. Изменение линейных размеров - усадка текстильных химических материалов происходит при воздействии на материал влаги и температуры, близкой к температуре термофиксации. Повышенная тепловая усадка материалов, появляющаяся в результате влажно-тепловой обработки, усложняет технологический процесс, увеличивает трудозатраты и материалоемкость при изготовлении изделий. Усадка более $2 \%$ приводит к переводу изделий в меньшие размеры. Тепловая усадка возрастает с увеличением количества тепловых воздействий на материал. С увеличением числа обработок от одной до семи усадка материалов может увеличиваться в 1,4-6 раз.

Предельные режимы влажно-тепловой обработки устанавливают в зависимости от вида ткани и технологической операции. Превышение установленных параметров режима приводит к появлению лас, пятен, опалов, тепловой усадки. Для отдельных материалов, например, синтетических, трикотажных и нетканых полотен, следует по возможности исключать влажно-тепловую обработку для получения объемной формы деталей. Объемная форма деталей должна создаваться путем конструкторских решений.

С целью уменьшения усадки материалов в текстильной промышленности в процессе отделки проводятся ширение, декатировка, обработка на специальных усадочных машинах, противоусадочное пропитывание, термофиксация тканей из синтетических волокон и смешанных тканей, содержащих синтетические волокна. В швейном производстве для придания усадки всему полотну производится декатировка.

\section{Выводы.}

Таким образом, при подборе материалов в пакет для корсетно-бельевых изделий [14] следует руководствоваться следующими принципами:

1. Использование материалов с одинаковой степенью растяжимости материала (настрачивание эластичного кружева на трикотаж или тканей со вставкой эластомерных нитей).

2. Использование материалов равных по поверхностной плотности (основной, подкладочный и прокладочный материалы). 


\begin{tabular}{|c|c|c|c|c|c|c|}
\hline \multirow{4}{*}{ Impact Factor: } & ISRA (India) & $=3.117$ & SIS (USA) & $=0.912$ & ICV (Poland) & $=6.630$ \\
\hline & ISI (Dubai, UAF & $=0.829$ & РИНЦ (Russia) & $=0.156$ & PIF (India) & $=1.940$ \\
\hline & GIF (Australia) & $=0.564$ & ESJI (KZ) & $=\mathbf{5 . 0 1 5}$ & IBI (India) & $=4.260$ \\
\hline & JIF & $=1.500$ & SJIF (Morocco) & $=5.667$ & & \\
\hline
\end{tabular}

3. Использование материалов равных по толщине (основной, подкладочный и прокладочный материалы).

4. Использование материалов равных по жесткости (основной, подкладочный и прокладочный материалы).

5. Использование материалов равных по степени усадки (основной, подкладочный и прокладочный материалы).

6. Использование высокоэластичных скрепляющих материалов (текстурированые нити) в местах, где изделие наиболее подвергается растяжению при эксплуатации.

С другой стороны, в процессе эксплуатации корсетно-бельевых изделий швы и строчки [15] подвергаются действию растягивающих и изгибающих сил, прикладываемых однократно и многократно и направленных вдоль и поперек швов. Из условий эксплуатации вытекают требования, предъявляемые к швам при пошиве изделий из эластичных материалов. Одним из основных требований, предъявляемых к швам [11] изделий, является их достаточная растяжимость. Растяжимость швов должна соответствовать тем деформациям, которые изделия испытывают в носке. Швы должны быть достаточно прочными при растяжении их как вдоль строчки, так и поперек нее. Стежки и строчки должны обеспечивать не только соединение деталей изделия, но оплетение срезов с целью их предохранения от осыпания и распускания трикотажа [16, 17].

Указанным выше требованиям в большей степени отвечают швы и строчки, выполняемые цепными стежками. Растяжимость и прочность строчек и швов зависят от вида стежков, из которых они образованы, структуры стежка, то есть степени затягивания швейных ниток в стежке, а также частоты строчки, ширины шва и растяжимости и прочности швейных ниток. Прочность строчки и шва также зависит от соответствия растяжимости строчки с растяжимостью материала.
Прочность швов, выполненных челночными стежками, при растяжении вдоль строчки зависит от прочности швейных ниток, структуры стежков и растяжимости материала. Удлинение швов, выполненных челночными стежками, составляет $10-15 \%$.

Строчки и швы, образованные однониточными и двухниточными цепными стежками, растягиваются в продольном направлении до $30-35 \%$ без разрыва строчки. Предел прочности на разрыв в продольном направлении соединительного шва, выполненного двухниточной цепной строчкой, приблизительно в 2 раза больше, чем такого же шва, выполненного челночной строчкой, а при растяжении в поперечном направлении - в 2,3 paзa.

Строчки, выполненные плоскими цепными трехниточными, пятиниточными, четырехниточными, девятиниточными стежками, обладают достаточной растяжимостью и прочностью для выполнения подшивочных, накладных и стачных швов. Строчки и швы, образованные краеобметочными стежками, обладают наиболее высокой по сравнению с другими видами цепных стежков растяжимостью вдоль строчки. Величина этой растяжимости достигает $40 \%$ и выше. Прочность швов также вполне достаточная.

Растяжимость и прочность строчек и швов зависят от частоты строчки. Частотой строчки называется количество стежков, приходящихся на 50 мм ее длины. Слишком малое число стежков вызывает обрыв швейных ниток при максимальном растяжении материала. Когда плотность стежков слишком высока, это сдерживает эластичность материала и снижается прочность шва в поперечном направлении. Оптимальное число стежков в строчке с учетом специфики изделия и свойств материала может быть определено экспериментально, то есть путем выполнения нескольких видов швов с последующим их растяжением по длине. Рекомендуемая частота строчек представлена в таблице 1.

Таблица 1. Рекомендуемая частота строчки при пошиве корсетно-бельевых изделий из полотен различных видов.

\begin{tabular}{|c|l|l|c|}
\hline \multirow{2}{*}{ Вид шва } & \multicolumn{1}{|c|}{ Вид стежка } & \multicolumn{1}{c|}{$\begin{array}{c}\text { Частота } \\
\text { Вид материала } \\
\text { строчки на 5 } \\
\text { см, не менее }\end{array}$} \\
\hline Соединительный & $\begin{array}{l}\text { Краеобметочный } \\
\text { трехниточный }\end{array}$ & $\begin{array}{l}\text { Из любого сырья, кроме } \\
\text { капроновых нитей }\end{array}$ & 22 \\
\cline { 2 - 5 } & Tо же & Из капроновых нитей & 25 \\
\cline { 2 - 5 } & $\begin{array}{l}\text { Плоский цепной } \\
\text { четырехниточный } \\
\text { пятиниточный }\end{array}$ & Изюбого сырья \\
\hline
\end{tabular}




\begin{tabular}{|c|c|c|c|c|c|c|}
\hline \multirow{4}{*}{ Impact Factor: } & ISRA (India) & $=3.117$ & SIS (USA) & $=0.912$ & ICV (Poland) & $=6.630$ \\
\hline & ISI (Dubai, UAE & $=0.829$ & РИНЦ (Russia) & $=0.156$ & PIF (India) & $=1.940$ \\
\hline & GIF (Australia) & $=0.564$ & ESJI (KZ) & $=\mathbf{5 . 0 1 5}$ & IBI (India) & $=4.260$ \\
\hline & JIF & $=1.500$ & SJIF (Morocco) & $=5.667$ & & \\
\hline
\end{tabular}

\begin{tabular}{|l|l|l|c|}
\hline & Зигзагообразный цепной & Из любого сырья & 35 \\
\hline \multirow{2}{*}{ Краевой подшивочный } & $\begin{array}{l}\text { Плоский } \\
\text { трехниточный цепной }\end{array}$ & $\begin{array}{l}\text { Из любого сырья, кроме } \\
\text { капроновых нитей }\end{array}$ & 22 \\
\cline { 2 - 4 } & Tо же & Из капроновых нитей & 25 \\
\cline { 2 - 5 } & $\begin{array}{l}\text { Краеобметочный } \\
\text { двухниточный }\end{array}$ & Из любого сырья & 22 \\
\hline Распошивочный & $\begin{array}{l}\text { Плоский } \\
\text { трехниточный цепной }\end{array}$ & Из любого сырья & 21 \\
\hline
\end{tabular}

Прочность любого соединительного шва зависит также от его ширины. Особенно большое влияние на прочность шва, а, следовательно, и на его качество оказывает ширина шва, выполненного краеобметочными стежками. При недостаточной ширине шва возможны разрыв нитей, их выползание из шва и распускание петель трикотажа. Ширина шва должна быть такой, чтобы шов предохранял нити материала от разрыва и выползания. Но, с другой стороны, необходимо иметь в виду, что излишняя ширина шва делает его грубым [18, 19].

\section{References:}

1. Afanas'yeva, A. I., Nefedova, L. V., Chalenko, E. A., \& Aksenova, I. V. (2015). Organizatsionno-tekhnicheskiye usloviya obnovleniya assortimenta v shveynom proizvodstve. Dizayn i tekhnologii, № 48 (90), 22-27.

2. Shpachkova, A. V., Andreeva, E. G., \& Chizhova, N. V. (2016). Kontrol' kachestva korsetno-bel'evykh izdelij. Innovatsii $i$ investitsii, № 5, 109-112.

3. (n.d.). Vliyanie svojstv materialov na tekhnicheskie protsessy izgotovleniya odezhdy. Retrieved 2018, from http://www.crosskpk.ru/ims/files/

4. Demskaya, A. A., Kirsanova, E. A., Vershinina, A. V., \& Chalenko, E. A. (2016). Vliyaniye svoystv materialov i metodov tekhnologicheskoy obrabotki na formirovaniye esteticheskogo vospriyatiya shveynykh izdeliy. Dizayn $i$ tekhnologii, № 53 (95), 51-56.

5. Safonova, N. S., \& Chalenko, E. A. (2015). Issledovaniye svoystv materialov dlya tseley proyektirovaniya plotnoprilegayushchikh shveynykh obolochek. V knige: Innovatsionnoye razvitiye legkoy i tekstil'noy promyshlennosti (INTEKS-2015) sbornik materialov Vserossiyskoy nauchnoy studencheskoy konferentsii. (pp. 104-106). Moskovskiy gosudarstvennyy universitet dizayna i tekhnologii.

6. Lisienkova, L. N., \& Kirsanova, E. A. (2010). Analiz deformatsionnogo sostoyaniya materialov dlya odezhdy $\mathrm{v}$ usloviyakh prostranstvennogo rastyazheniya. Izvestiya vysshikh uchebnykh zavedenij. Tekhnologiya tekstil'noj promyshlennosti, № 2, 28-30.

7. Aksenova, I. A., et al. (2015). Analiz svojstv nitok, primenyaemykh dlya stachivaniya detalej obolochek plotnogo prileganiya (tezisy). Dizajn, tekhnologii i innovatsii $\mathrm{v}$ tekstil'noj i legkoj promyshlennosti (INNOVATSII-2015): sbornik materialov Mezhdunarodnoj nauchnotekhnicheskoj konferentsii. CHast' 2. (pp.4-6). M.: FGBOU VPO «MGUDT».

8. (n.d.). Izgotovlenie odezhdy iz trikotazhnogo polotna. Retrieved 2018, from http://www.kustar.ru

9. Flerova, L. N., \& Surikova, G. I. Materialovedenie trikotazha. (pp.112-114). M.: Legkaya industriya.

10. Abu Sakr Vadikh, Kirsanova, E. A., Maksimenko, R. V., \& Makharashvili, G. E. (2011). Izmenenie svojstv tekstil'nykh materialov pri vozdejstvii tekhnologicheskikh faktorov. Dizajn i tekhnologii, № 23 (65), 83-86.

11. Chalenko, E. A., Kirsanova, E. A., \& Vershinina, A. V. (2016). Nadezhnost' soyedineniya detaley pri dinamicheskikh nagruzkakh $v$ sportivnykh izdeliyakh. V sbornike: Modelirovaniye $\mathrm{v}$ tekhnike i ekonomike sbornik materialov mezhdunarodnoy nauchno-prakticheskoy konferentsii. Glavnyy redaktor: Vankevich E.V. (pp. 185-187).

12. Kirsanova, E. A., \& Chalenko, E. A. (2016). Modelirovaniye svoystv materialov legkoy promyshlennosti $v$ zavisimosti ot formy izdeliy. 


\begin{tabular}{|c|c|c|c|c|c|c|}
\hline \multirow{4}{*}{ Impact Factor: } & ISRA (India) & $=3.117$ & SIS (USA) & $=0.912$ & ICV (Poland) & $=6.630$ \\
\hline & ISI (Dubai, UAE & $=0.829$ & РИНЦ (Russia) & $=0.156$ & PIF (India) & $=1.940$ \\
\hline & GIF (Australia) & $=0.564$ & ESJI (KZ) & $=\mathbf{5 . 0 1 5}$ & IBI (India) & $=4.260$ \\
\hline & JIF & $=1.500$ & SJIF (Morocco) & $=5.667$ & & \\
\hline
\end{tabular}

V sbornike: Aktual'nyye napravleniya fundamental'nykh i prikladnykh issledovaniy Materialy VIII mezhdunarodnoy nauchnoprakticheskoy konferentsii. (pp. 62-65).

13. Chalenko, E. A. (2017). Vliyaniye tekhnologicheskoy obrabotki na svoystva materialov dlya izgotovleniya shveynykh izdeliy. V sbornike: Rezul'taty sovremennykh nauchnykh issledovaniy i razrabotok sbornik statey pobediteley II Mezhdunarodnoy nauchnoprakticheskoy konferentsii. (pp. 61-63).

14. Bordacheva, A. A., Aksenova, I. V., Chalenko, E. A., \& Galayan, A. G. (2014). Issledovanie assortimenta i klassifikatsiya materialov dlya izgotovleniya zhenskikh bel'evykh izdelij. Dizajn i tekhnologii, № 39 (81), 34-40.
15. (1988). GOST 12807-88. Izdeliya shvejnye. Klassifikatsiya stezhkov, strochek $i$ shvov. M.: Izdatel'stvo standartov.

16. Flerova, L. N., Golikova, T. V., \& Zolottseva, L. V. (1976). Tekhnologiya trikotazhno-shvejnogo proizvodstva. (pp.57-65). M.: Legkaya industriya.

17. (1991). Instruktsiya. Tekhnicheskie trebovaniya $k$ soedineniyam detalej shvejnykh izdelij. M.

18. (1987). GOST 10399-87 Izdeliya trikotazhnye bel'evye. Trebovaniya $k$ poshivu. M.: Izdatel'stvo standartov.

19. Platova, A. A., Chalenko, E. A., Kirsanova, E. A., \& Kupriyanova, M. S. (2012). Vzaimosvyaz' svoystv materialov i tekhnologicheskogo protsessa izgotovleniya zhenskikh bel'yevykh i korsetnykh izdeliy. Dizayn i tekhnologii, № 30 (72), 98-103. 